\title{
Intramolecular thiolysis of 4-mercaptobutyrate esters: developing a "traceless" linker for alcohol release from self-assembled monolayers on gold
}

\author{
Max B. Buchmann, Thomas M. Fyles,* Trevor Mischki, Todd Sutherland, Christine C. \\ Tong, and Vivian L.Y. Yip
}

Chemistry Department, University of Victoria, P.O. Box 3065, Victoria, B.C., Canada, V8W 3V6

E-mail: tmf@uvic.ca

Dedicated to Oswald S. Tee on the occasion of his $60^{\text {th }}$ birthday, and in recognition to his many contributions to chemistry in Canada

(received 27 Aug 01; accepted 09 Oct 01; published on the web 17 Oct 01)

\begin{abstract}
A series of esters of dithiobutyric acid was prepared using the carbodiimide coupling system. These esters were used to examine the kinetic feasibility of release of alcohols by reductive cleavage of the disulfide. Release of p-nitrophenol was rapid following reduction with dithiothreitol at $\mathrm{pH} \sim 10.5$. Intramolecular thiolysis is at least one hundred-fold faster then base hydrolysis at this $\mathrm{pH}$. NMR experiments established rapid alcohol release for phenolates and ethanolamine derivatives but alkyl substrates were found to release slowly. Self-assembled monolayers (SAMs) formed from nitrophenol or ethanolamine derivatives produce the expected quantity of alcohol following reductive release from gold powder.
\end{abstract}

Keywords: Intramolecular thiolysis, 4-mercaptobutyrate esters, self-assembled monolayers, dithiobutyric acid esters carbodiimide coupling system

\section{Introduction}

Ion channels in planar bilayers offer a way to observe single molecular events. Typically a vast excess of putative channel forming compound is added in the hope of haphazardly inserting a single channel into a planar bilayer. We seek a method to reliably embed a few molecules into a lipid bilayer. To provide a high level of control over channel deposition we envisage release from a gold electrode via reductive cleavage of a gold-sulfur bond. Conventional microelectrodes and circuitry would be capable of delivering as few as $10^{2}$ electrons. Figure 1 introduces the concept of a "traceless" linker, providing a method of selectively delivering a few molecules at a defined point and time via a thiolactonization release of the channel compound as a bound alcohol. 


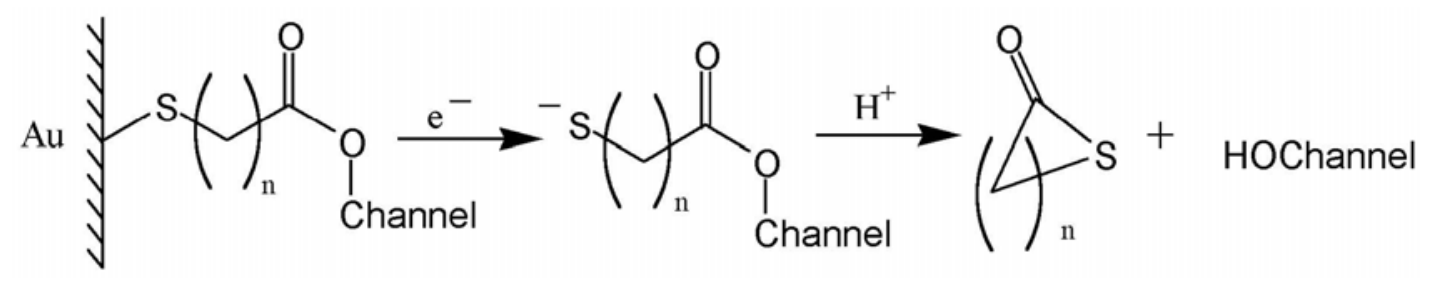

Figure 1. Proposed Pathway for Release of Channel Compounds.

The adsorption of dialkyl disulphides has been established ${ }^{1,2}$ with the formation of goldsulfur bonds at the expense of the sulfur-sulfur bond. Spontaneous formation of self-assembled monolayers (SAMs) based on the formation of gold-sulfur bonds was pioneered by Nuzzo and Allara in $1983 .{ }^{3}$ Some reports have also established the reductive destruction of SAMs via reductive cleavage of the gold-sulfur bond. ${ }^{4-10}$

In order for the "traceless" linker to be effective, a process for reductively cleaving the goldsulfur bond and simultaneously releasing the alcohol is required. As suggested in Figure 1, thiolactone was evaluated for its potential to release the alcohol after reductive cleavage of the gold-sulfur bond. Results by Schjånberg ${ }^{11}$ show that the rate of lactonization for 4mercaptobutanoic acid is comparable to the rate of hydrolysis of this ester, and that at equilibrium the ratio of $\gamma$-thiolactone: 4-mercaptobutanoic acid is nearly $1: 1$ at $\mathrm{pH} 1$. The rate for hydrolysis of the $\delta$-lactone of 5-mercaptopentanoic acid results primarily in the mercaptocarboxylate form at equilibrium at the same $\mathrm{pH}^{11}$ This indicates that 4mercaptobutanoic acid linker $(n=3$ in Figure 1) would be favoured for an intramolecular nucleophilic catalysis of alcohol release. A conformationally restricted example of such a nucleophilic catalysis was reported by $\mathrm{Fife}^{12}$ for the release of nitrophenolate from a 2mercaptophenyl carbamate, also via $\gamma$-thiolactone intermediate.

The goal of this study was to establish alcohol release occurs as required and that release occurs at a competent rate for the application envisaged. Working with phenol esters we established that phenolate release, following reduction of the disulfide bond by dithiothreitol (DTT), occurs and is not rate determining. The ability to release other alcohols was shown by NMR scale thiolactonization reactions initiated by DTT. With release of alcohols by thiolactonization established, monolayers were formed on gold surfaces, reductively cleaved, and the expected alcohols were detected both by UV/VIS spectrometry and by HPLC analysis.

\section{Results and Discussion}

\section{Synthesis of dithiobutyrate diesters}

Five esters were prepared as shown in scheme 1. The yields ranged from $35 \%$ to $56 \%$ and represent the isolation of the di-substituted esters except in the case of Fmoc-ethanolamine in which the $62 \%$ yield is the combined yield for the synthesis and isolation of both mono and di- 
substituted esters. All products were fully characterised by conventional techniques.

\section{Kinetics of phenolate release in solution}

The initial focus of this study was the rate of p-nitrophenolate release from reductive cleavage of 1 as this release provided a simple spectroscopic probe. Chemical reductive cleavage of the disulphide bond was envisaged, followed by thiolysis of the ester as indicated in scheme 2. No simple method of reduction was found near neutral $\mathrm{pH}$ and reagents required basic conditions to be effective. Sodium borohydride, sodium cyanoborohydride, and triphenylphosphine were evaluated and were shown to be ineffective or kinetically incompetent as reducing agents for the disulphide bond at $\mathrm{pH}$ 7. Initial testing showed that dithiothreitol (DTT) in 6:4 water: acetonitrile at a $\mathrm{pH}$ of 10.4 , was an effective reducing agent for the disulphide bond.
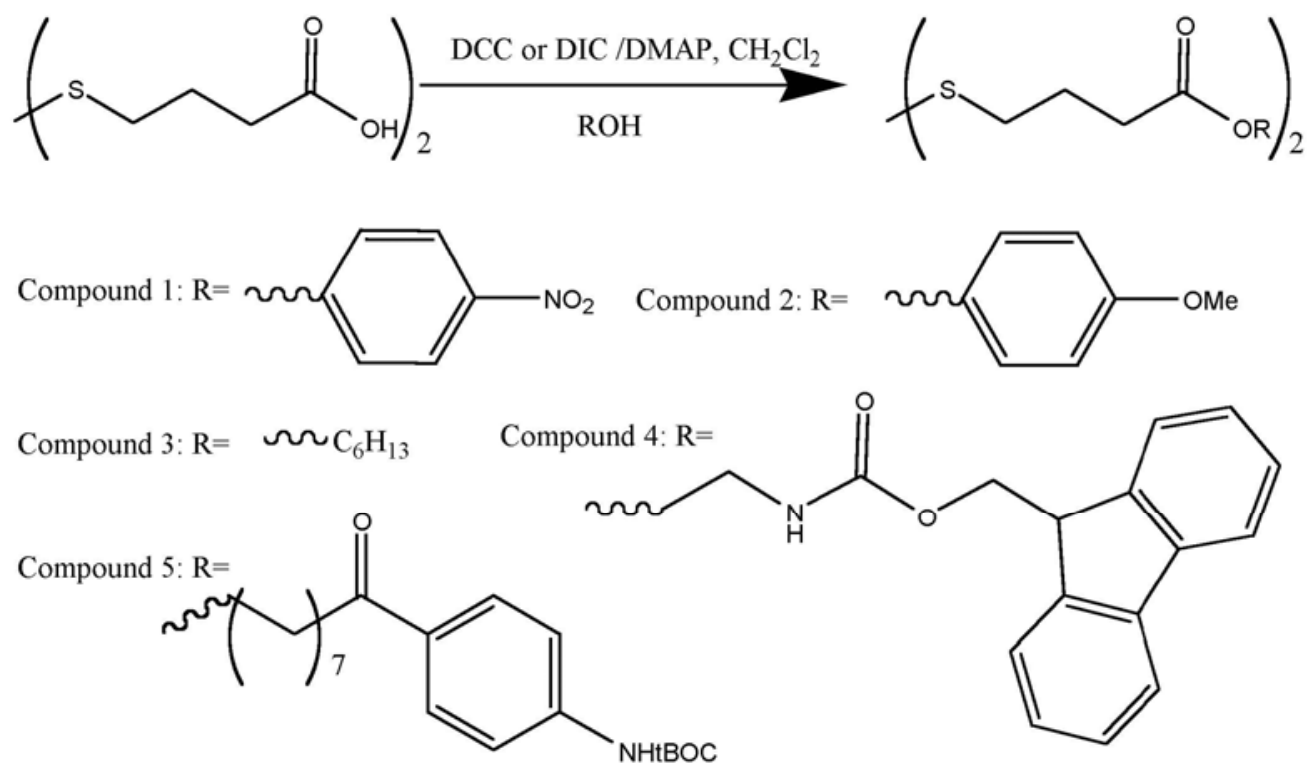

\section{Scheme 1}

\section{Scheme 2}

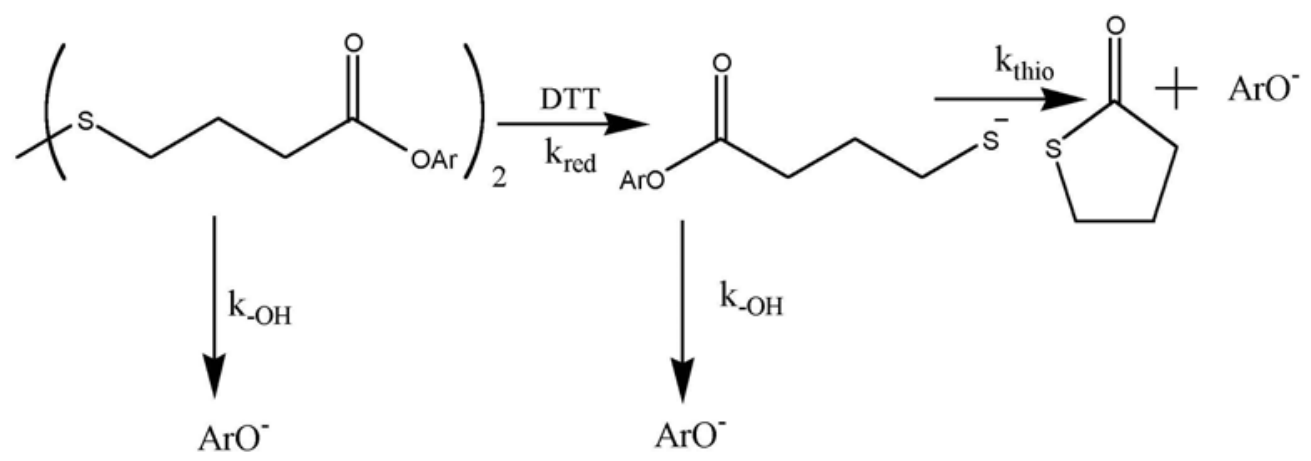

The observed pseudo first order rate of base hydrolysis in an acetonitrile/water buffer solution at $\mathrm{pH} 10.4$ was established to be $21.9 \pm 0.7 \mathrm{~s}^{-1}$. This result gave a half-life for base hydrolysis of $3200 \mathrm{~s}$ in the absence of DTT. 
By varying the concentrations of disulphide and DTT, the kinetic competence of the thiolysis was established (Table 1). This experiment was conducted by adding 6 parts of aqueous solution containing 1eq. DTT, and 1.5 eq. sodium hydroxide, to 4 parts acetonitrile containing 1 eq. of disulphide.

Table 1. Average rate constants for nitrophenolate release according to Scheme 2. $\left(6: 4 \mathrm{CH}_{3} \mathrm{CN} /\right.$ $\mathrm{H}_{2} \mathrm{O}$ at $\mathrm{pH} 10.4,25^{\circ} \mathrm{C}$ )

\begin{tabular}{ccc}
\hline $\begin{array}{c}\text { DTT } \\
\left(\mathrm{M} \times 10^{3}\right), \text { eq. }\end{array}$ & $\begin{array}{c}\text { Disulfide } \\
\left(\mathrm{M} \times 10^{5}\right)\end{array}$ & $\mathrm{k}_{\text {obs }} \pm \mathrm{S}_{\mathrm{x}} \times 10^{3}$ \\
\hline $2.00,100$ & 2.00 & $32.2 \pm 2.5$ \\
$1.00,100$ & 1.00 & $13.67 \pm 0.19$ \\
$1.00,50$ & 2.00 & $15.2 \pm 0.4$ \\
$0.80,100$ & 0.80 & $11.2 \pm 1.0$ \\
$0.40,100$ & 0.40 & $6.0 \pm 1.2$ \\
$0.40,20$ & 2.00 & $5.6 \pm 0.3$ \\
$0.20,100$ & 0.20 & $2.46 \pm 0.11$ \\
$0.20,10$ & 2.00 & $2.8 \pm 0.3$ \\
\hline
\end{tabular}

DTT induced release of phenolates was shown to proceed with a half-life below $600 \mathrm{~s}$. As reported by Whitesides for DTT reduction of other disulfides, ${ }^{13}$ the overall reaction was shown to be first order in both disulfide and DTT (Table 1). Under equivalent disulfide concentrations there is an apparent 100-fold decrease in the half-life for phenolate release (22s vs. 3000s) compared to the direct hydrolysis. No precise estimate of kthio (as defined in scheme 2) was possible, but these experiments establish the kinetic competence of scheme 2 as a means to release phenolate into solution.

\section{NMR Scale thiolactonization experiments}

The DTT cleavage of the disulphide bond of $\mathbf{1}$ was conducted in deuterated acetonitrile. The DTT was added with 1.5 equivalents of $\mathrm{NaOD}$ in $\mathrm{D}_{2} \mathrm{O}$. This cleavage resulted in the release of $\mathrm{p}$ nitrophenolate in less than 5 minutes. At this stoichiometric ratio the reaction proceeds to an equilibrium mixture of disulfide esters and mercaptobutyrates. If intramolecular thiolysis were slow, then the direct observation of a thiolate ester would be possible. If thiolysis proceeded quickly, then the only the mercaptobutyrate would be evident.

Figure 2(a) shows the ${ }^{1} \mathrm{H}-\mathrm{nmr}$ spectrum of 1 in $\mathrm{CD}_{3} \mathrm{CN}$. The aromatic protons are at 8.25 ppm and $7.34 \mathrm{ppm}$. Three methylene signals were present: two protons $\alpha$ to ester $(2.74 \mathrm{ppm})$, two protons $\beta$ to the ester $(2.11 \mathrm{ppm})$, and the two protons $\alpha$ to the disulfide $(2.83 \mathrm{ppm})$. Figure 2(c) shows the ${ }^{1} \mathrm{H}$-nmr of $\mathrm{p}$-nitrophenolate under the same conditions with two aromatic signals at $7.92 \mathrm{ppm}$ and $6.36 \mathrm{ppm}$. Figure 2(b) shows the ${ }^{1} \mathrm{H}-\mathrm{nmr} 5$ minutes after the addition of 1.1 equivalents of basic DTT to the deuterated acetonitrile solution of the disulphide. Two new resonances $(8.01 \mathrm{ppm}$ and $6.63 \mathrm{ppm})$ indicate the appearance of pnitrophenolate signals, while 
two resonances $(8.24 \mathrm{ppm}$ and $7.33 \mathrm{ppm})$ show the presence of unreleased p-nitrophenolate ester. The appearance of three new signals $(2.65 \mathrm{ppm}, 2.41 \mathrm{ppm}$, and $2.21 \mathrm{ppm})$ represents the appearance of the mercaptobutyrate ion. The methylene positions from the disulfide ester remain (2.83ppm, $2.74 \mathrm{ppm}$, and $2.10 \mathrm{ppm})$. The presence of thiolactone is not observed as the mercaptobutyrate form dominates the equilibrium under the conditions of the reaction $(\mathrm{pH}$ 10.3). The dithiothreitol reagent also contributes resonances to Figure 2(b), these are found around $3.5 \mathrm{ppm}$. This reaction was also conducted in deuterated methanol with a similar result. This NMR experiment confirms the kinetic result above, namely that phenolate is rapidly released, presumably via intramolecular thiolysis.

In contrast, the DTT cleavage of the hexyl ester 3 in deuterated methanol resulted in cleavage of the disulphide bond with no release of the deprotonated hexanol. This was clearly observable as the resonance for the methylene protons next to the disulphide shifted from 2.73 ppm to 2.50 ppm, while the hexyl methylene protons next to the ester remain close to $4.08 \mathrm{ppm}$. This is a direct observation of a stable thiolate ester that indicates the expected thiolysis/ hydrolysis does not occur rapidly in this instance.

Other esters show a range of behaviors between these two limits. p-Methoxyphenol is released quickly from 2(under 10 minutes), and Fmoc-ethanolamine is released at a feasible rate from 4(under 30 minutes). The long chain alcohol from 5 bola was shown to release very slowly, and showed complete conversion after 3 days, a rate consistent with direct hydrolysis.
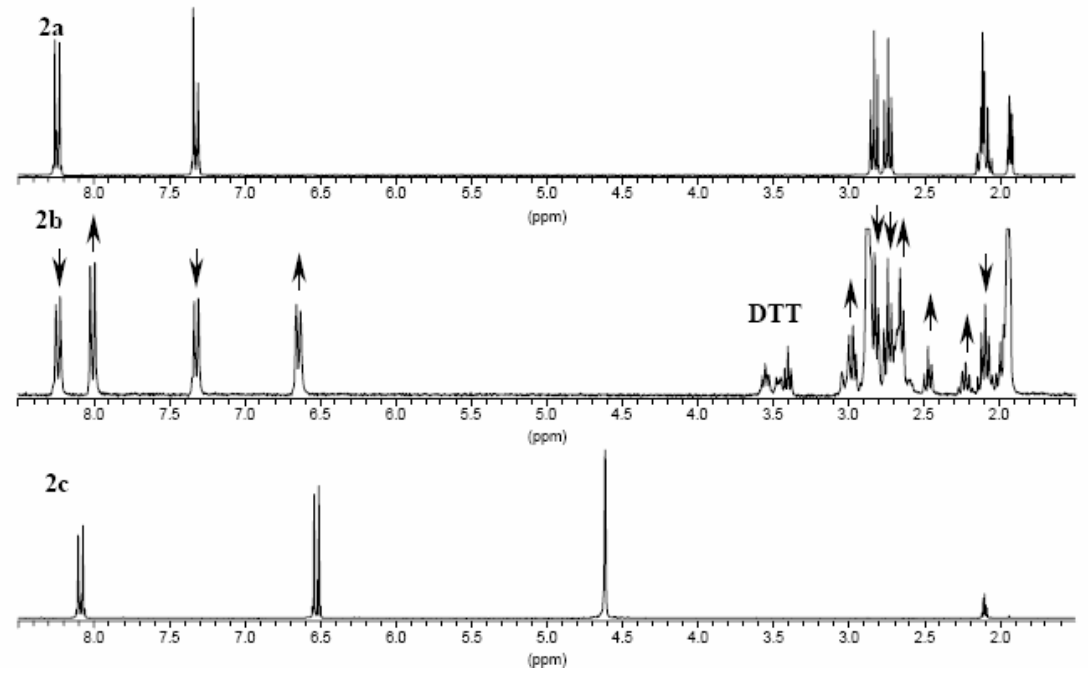

Figure 2: ${ }^{1} \mathrm{H}-\mathrm{nm}$ Analysis of DTT Cleavage of Bis-(p-nitrophenol)-4-4-dithiodibutanoate (1)

a) (1) in $\mathrm{CD}_{3} \mathrm{CN}$

b) 1 eq. of (1) plus 1.1 eq. DTT plus 1.5 eq. $\mathrm{NaOD}$ in $\mathrm{CD}_{3} \mathrm{CN}$

c) p-nitrophenol plus $\mathrm{NaOD}$ in $\mathrm{CD}_{3} \mathrm{CN}$

\section{Reductive cleavage and release from gold powders}

Experimental detection of reductive release from gold requires a sufficient surface area to 
produce a detectable amount of product. A convenient form is the use of spherical gold powder (5.5-9.0 micron) with a surface area of 345 to $565 \mathrm{~cm}^{2} / \mathrm{g}$. At a surface concentration of $10^{14}$ molecules $/ \mathrm{cm}^{2}$ this corresponds to release of 57 nanomoles of material per gram of gold powder. Electrolysis of the suspended powder in a $\mathrm{ml}$ or less of electrolyte solution will then give a concentration of approximately $60 \mu \mathrm{M}$ per gram of gold powder.

Spherical gold powder was cleaned, and absorption was conducted overnight in a dichloromethane solution of $\mathbf{1}$ (approx. 0.1 M). The gold powder was rinsed until the presence of 1 was undetectable by UV spectrometry. The release was conducted in 1M KCL solution, at a potential of $-2.0 \mathrm{~V}$ (vs. $\mathrm{AgCl} / \mathrm{Ag}$ reference) applied for $30 \mathrm{sec}$. The release solution turned visibly yellow, and UV/VIS spectrometry confirmed the presence of pnitrophenolate. Although the result was gratifying, the amount of nitrophenolate was much higher then expected, probably due to carryover from the absorption step.

Fluorescence detection was then used to improve the detection of the residual disulfide to confirm negligible carryover. Absorption of $\mathbf{4}$ was conducted in ethanol, and reductive cleavage was conducted in acetonitrile solution. Analysis by LC showed release of a quantity of Fmocethanolamine corresponding to approximately $10 \%$ of the expected release and represents the overall effectiveness of the process outlined in Figure 1. Since our goal is to limit the amount of material released, this efficiency is acceptable.

The overall fitness of Figure 1 is thus established. The next stage will be to prepare a suitable mercaptobutyrate ester of a channel-forming compound and proceed to a controlled embedding in a planar bilayer. Our efforts in this are will be reported in due course.

\section{Experimental Section}

General Procedures. All NMR spectra were recorded on a Bruker AC300 FT NMR spectrometer. ${ }^{1} \mathrm{H}-\mathrm{NMR}$ and ${ }^{13} \mathrm{C}-\mathrm{NMR}$ were referenced to the solvent residual peaks as follows: $\mathrm{CDCl}_{3} \delta_{\mathrm{H}} 7.26, \delta \mathrm{C} 77.16, \mathrm{CD}_{3} \mathrm{CN} \delta_{\mathrm{H}} 1.94$, and $\mathrm{CD}_{3} \mathrm{OD} \delta_{\mathrm{H}} 3.31$. UV/VIS spectra were recorded on a Cary50 UV/VIS spectrometer.

Bis-(p-nitrophenyl) 4,4-dithiodibutanoate (1). Dicyclohexylcarbodiimide (DCC) (1.91 mg, $9.23 \mathrm{mmol}$ ) was added to a $100 \mathrm{ml}$ round bottom flask and dissolved in methylene chloride $(50 \mathrm{ml})$; and 4-dimethylamino pyridine $(122 \mathrm{mg}, 0.92 \mathrm{mmol})$ and 4,4-dithiodibutyric acid $(1.00 \mathrm{~g}$, $4.2 \mathrm{mmol}$ ) were added. The disulphide did not dissolve, it was stirred for 5 minutes and pnitrophenol (1.28g, 9.23mmol) was added. The mixture was stirred for 30 hours. The solid (urea) was removed by vacuum filtration. The filtrate was washed with an aqueous solution of $\mathrm{NaHCO}_{3}$ $/ \mathrm{Na}_{2} \mathrm{CO}_{3}(4 \times 25 \mathrm{ml})$ to remove unreacted phenol. The organic layer was washed with brine $(1 \times$ $50 \mathrm{ml})$, dried $\left(\mathrm{MgSO}_{4}\right)$ and concentrated under reduced pressure to afford a yellow oil $(2.5 \mathrm{~g})$. The crude oil was purified by silica chromatography (methylene chloride) to afford an orange oil. The oil was triturated with diethyl ether and a light yellow solid (1.0962g, 52\% yield), 
melting point $80-81{ }^{\circ} \mathrm{C} .{ }^{1} \mathrm{H}-\mathrm{NMR} \mathrm{CDCl}_{3} \delta 8.24(2 \mathrm{H}, \mathrm{m}), \quad 7.26(2 \mathrm{H}, \mathrm{m}), 2.80(2 \mathrm{H}, \mathrm{t}, \quad J=7.0 \mathrm{~Hz})$, $2.75(2 \mathrm{H}, \mathrm{t}, J=7.4 \mathrm{~Hz}), 2.16(2 \mathrm{H}, J=7.3 \mathrm{~Hz}) .{ }^{13} \mathrm{C}-\mathrm{NMR} \mathrm{CDCl}_{3} \delta 170.6,155.3,145.3,125.2,122.4$, 37.3, 32.5, 23.8. MS FAB $\left(\mathrm{M}^{-} \bullet\right): 480.0$.

Bis-(p-methoxyphenyl) 4,4-dithiodibutanoate (2). Dicyclohexylcarbodiimide (DCC) (953 mg, $4.62 \mathrm{mmol}$ ) was added to a $50 \mathrm{ml}$ round bottom flask and dissolved in methylene chloride $(20 \mathrm{ml})$; and 4-dimethylamino pyridine $(56.2 \mathrm{mg}, 0.46 \mathrm{mmol})$ and 4,4-dithiodibutyric acid (500mg, $2.1 \mathrm{mmol}$ ) were added. The disulphide did not dissolve, it was stirred for 5 minutes and p-methoxyphenol $(573,4.62 \mathrm{mmol})$ was added. The mixture was stirred for 30 hours. The solid (urea) was removed by vacuum filtration. The filtrate was washed with an aqueous solution of $\mathrm{NaHCO}_{3} / \mathrm{Na}_{2} \mathrm{CO}_{3}(3 \times 20 \mathrm{ml})$. The organic layer was washed with brine $(1 \times 20 \mathrm{ml})$, dried $\left(\mathrm{MgSO}_{4}\right)$ and concentrated under reduced pressure to afford a yellow oil. The crude oil was purified by silica chromatography ( $5 \%$ ethyl acetate: methylene chloride) to afford an amber oil. The oil was triturated with diethyl ether and hexane to afford a white solid (504mg, 53\% yield), melting point $63-64^{\circ} \mathrm{C} .{ }^{1} \mathrm{H}-\mathrm{NMR} \mathrm{CDCl}_{3} \delta 6.98(2 \mathrm{H}, \mathrm{m}), 6.86(2 \mathrm{H}, \mathrm{m}), 3.77(3 \mathrm{H}, \mathrm{s}), 2.80(2 \mathrm{H}, \mathrm{t}, \mathrm{J}$ $=7.0 \mathrm{~Hz}), 2.67(2 \mathrm{H}, \mathrm{t}, J=7.4 \mathrm{~Hz}), 2.16(2 \mathrm{H}$,quintet, $J=7.3 \mathrm{~Hz}) .{ }^{13} \mathrm{C} \mathrm{NMR} \mathrm{CDCl}_{3} \delta 171.9,157.2$, 157.2, 144.1; 122.2, 114.4, 55.6, 37.6, 32.6, 24.1. MS FAB $\left(\mathrm{MH}^{+}\right): 451.1$.

Dihexyl 4,4-dithiodibutanoate (3). Was prepared as above, except 16 hour reaction time and purified by silica chromatography (10\% ethyl acetate: toluene) to afford a pale yellow oil. The oil was triturated with diethyl ether to afford a clear oil (35\% yield). ${ }^{1} \mathrm{H}-\mathrm{NMR} \mathrm{CDCl}_{3} \delta 4.06(4 \mathrm{H}$, $\mathrm{t}, J=6.6), 2.71(4 \mathrm{H}, \mathrm{t}, J=7.4), 2.43(4 \mathrm{H}, \mathrm{t}, J=7.4), 2.02(4 \mathrm{H}, \mathrm{m}), 1.62(4 \mathrm{H}, \mathrm{m}), 1.31(12 \mathrm{H}, \mathrm{m})$, $0.89(6 \mathrm{H}, \mathrm{m})$. MS FAB $\left(\mathrm{M}^{\bullet}\right): 405.2$.

Bis-(Fmoc-aminoethyl) 4,4-dithiodibutanoate (4). Was prepared in a similar manner above, except diisopropylcarbodiimide (DIC) was used as the coupling reagent and the reaction was conducted for 3 hours. Purification was done by silica chromatography (5:1 dichloromethane: ethyl acetate) to afford a two components, both pale yellow oils. (13\% yield of di-substituted product, and 49\% mono-substituted product). ${ }^{1} \mathrm{H}-\mathrm{NMR} \mathrm{CDCl}_{3} \delta 7.75(4 \mathrm{H}, \mathrm{m}), 7.57(4 \mathrm{H}, \mathrm{m})$, $7.40(4 \mathrm{H}, \mathrm{m}), 7.30(4 \mathrm{H}, \mathrm{m}), 4.40(4 \mathrm{H}, \mathrm{d}, J=6.6), 4.16(4 \mathrm{H}, \mathrm{m}), 3.44(4 \mathrm{H}, \mathrm{d}, J=5.5), 2.70(4 \mathrm{H}, \mathrm{t}$, $J=7.0), 2.45$ (4H, t $J=7.40), 2.04(4 \mathrm{H}, \mathrm{m}), 1.26(2 \mathrm{H}, \mathrm{d}, J=12.5)$. MS FAB $\left(\mathrm{MH}^{+}\right): 769.3$.

Bis-[8-(4-\{t-Boc-amino\}phenoxy)octyl] 4,4-dithiodibutanoate (5). Was prepared as above except using DIC as the coupling reagent with a 5-day reaction time. Purification was done by silica chromatography (1:1 petroleum ether: ethyl acetate) a waxy white solid. (56\% yield). ${ }^{1} \mathrm{H}$ $\mathrm{NMR} \mathrm{CDCl}_{3} \delta 7.97(4 \mathrm{H}, \mathrm{m}), 7.43(4 \mathrm{H}, \mathrm{m}), 4.28(4 \mathrm{H}, \mathrm{t}, J=7.0), 4.06(4 \mathrm{H}, \mathrm{t}, J=6.6), 2.71(4 \mathrm{H}, \mathrm{t}, J$ $=7.0), 2.43(4 \mathrm{H}, \mathrm{t}, J=7.4), 2.01(4 \mathrm{H}, \mathrm{m}), 1.73(4 \mathrm{H}, \mathrm{m}), 1.62(4 \mathrm{H}, \mathrm{m}), 1.34(18 \mathrm{H}, \mathrm{m}), 1.26(16 \mathrm{H}$, m). MS FAB $\left(\mathrm{M}^{-} \bullet\right): 932.4$.

NMR scale thiolactonization experiments. DTT $(1.1 \mathrm{mg}, 0.0076 \mathrm{mmol})$ was dissolved in $1.5 \mathrm{ml} \mathrm{CD}{ }_{3} \mathrm{CN}$, with $0.075 \mathrm{ml}$ of $0.151 \mathrm{M} \mathrm{NaOD} / \mathrm{D}_{2} \mathrm{O}(0.0113 \mathrm{mmol})$, and 1 (3.1 $\mathrm{mg}$, $0.0064 \mathrm{mmol}$ ) was dissolved in $1.5 \mathrm{ml} \mathrm{CD}{ }_{3} \mathrm{CN}$. The ${ }^{1} \mathrm{H}-\mathrm{nmr}$ spectra for the two solutions were recorded and then the solutions were mixed, and the ${ }^{1} \mathrm{H}-\mathrm{nmr}$ spectrum collected after 5 minutes indicated the reaction was completed. Other compounds were examined in an identical manner.

Quantification of reductively cleaved Fmoc-ethanolamine. Compound 4 (50.0 mg) was 
dissolved in $3.0 \mathrm{ml}$ of ethanol $\left(2.17 \times 10^{-2} \mathrm{M}\right)$. Spherical gold powder $(0.350 \mathrm{~g}$., 5.5-9.0 micron, $99.96+\%$ metals basis) was cleaned in a $1: 1$ solution of $30 \%$ hydrogen peroxide and sulfuric acid. The gold powder was extensively rinsed with water and ethanol, and then placed overnight in the disulphide solution. The gold powder was then removed and extensively rinsed with ethanol, water, and acetonitrile until washings contained undetectable amounts of the UV and fluorescent active Fmoc group. The gold powder was then placed in $1.0 \mathrm{ml}$ of a $0.5 \mathrm{M}$ solution of lithium perchlorate in acetonitrile. The gold powder was suspended by sonication while a potential of -2.0 Volts (versus a $0.1 \mathrm{M} \mathrm{AgNO}_{3} / \mathrm{CH}_{3} \mathrm{CN} / \mathrm{Ag}$ reference electrode) was applied for $180 \mathrm{sec}$.

Following the addition of a $5 \mu 12.0 \times 10^{-2} \mathrm{M}$ phenol standard to the $1.0 \mathrm{ml}$ of release sample, a $20.0 \mu \mathrm{l}$ aliquot of the mixture was injected on a C-18 column $(250 \mathrm{~mm} / 4 \mathrm{~mm}$ Nucleosil $5 \mu \mathrm{m}$ C18), with a initial flow of $1: 1 \mathrm{H}_{2} \mathrm{O}: \mathrm{CH}_{3} \mathrm{CN}$ (both containing $0.1 \% \mathrm{TFA}$ ), which after 1 min. was ramped over 8 minutes to $100 \%$ acetonitrile. Phenol eluted after $3.26 \mathrm{~min}$ and Fmocethanolamine eluted after $5.54 \mathrm{~min}$. A calibration curve was prepared using fluorescence detection (excitation: $270 \mathrm{~nm}$, emission: $305 \mathrm{~nm}$ ), and indicated that a total of $2 \times 10^{-9}$ mole of Fmoc-ethanolamine had been released into the $1 \mathrm{ml}$ solution.

\section{Acknowledgements}

We the authors are grateful for ongoing support from the National Science and Engineering Research Council for research grants and financial support of summer students. The alcohol for compound 5 was a gift from Paul Eggers.

\section{References}

1. Nuzzo, R. G.; Zegarski, B. R.; Dubois, L. H. J. Amer. Chem. Soc. 1987, 109, 733.

2. Dubois, L. H.; Nuzzo, R. G. Annu. Rev. Phys. Chem. 1992, 43, 437.

3. Nuzzo, R. G.; Allara, D. L. J. Am. Chem. Soc. 1983, 105(13), 4481.

4. Walczak, M. M.; Popenoe, D. D.; Deinhammer, R. S.; Lamp, B. D.; Chung, C. K.; Porter, M. D. Langmuir 1991, 7, 2687.

5. Schneider, T. W.; Buttry, D. A. Abstr. Pap. Am. Chem. Soc. 1992, 203, 34.

6. Yang, D. F.; AlMaznai, H.; Morin, M. J. Phys. Chem. B 1997, 101, 1158.

7. Zhong, C. J.; Zak, J.; Porter, M. D. J. Electroanal. Chem. 1997, 421, 9.

8. Imabayashi, S.; Iida, M.; Hobara, D.; Feng, Z. Q.; Niki, K.; Kakiuchi, T. J. Electroanal. Chem. 1997, 428, 33.

9. Yang, D. F.; Morin, M. J. Electroanal. Chem. 1998, 441, 173.

10. Kawaguchi, T.; Yasuda, H.; Shimazu, K.; Porter, M. D. Langmuir 2000, 16, 9830.

11. Schånberg, E. Ber. 1942, 75B, 468.

12. Fife, T. H; Hutchins, J. E. C.; Wang, M.S. J. Am. Chem. Soc. 1975, 97, 5878.

13. Houk, J.; Singh, R.; Whitesides, G.M. Meth. Enz. 1987, 143, 129. 